\title{
Tensile Strength and Moisture Resistance Properties of Biocomposite Films Based on Polyvinyl Alcohol (PVA) with Cellulose as Reinforcement from Durian Peel Fibers
}

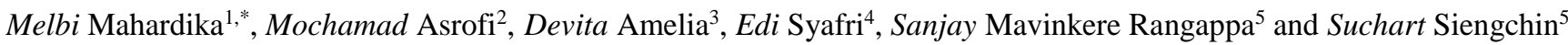 \\ ${ }^{1}$ Department of Biosystems Engineering, Institut Teknologi Sumatera, South Lampung, 35365, Indonesia \\ ${ }^{2}$ Department of Mechanical Engineering, University of Jember, Jember, 68121, Indonesia \\ ${ }^{3}$ Department of Chemical Engineering, Institut Teknologi Sumatera, South Lampung, 35365, Indonesia \\ ${ }^{4}$ Department of Agricultural Technology, Agricultural Polytechnic, Payakumbuh, West Sumatra 26271, Indonesia \\ ${ }^{5}$ Natural Composites Research Group Lab, Department of Materials and Production Engineering, The Sirindhorn International Thai- \\ German Graduate School of Engineering, King Mongkut's University of Technology North Bangkok, Bangkok, 10800, Thailand
}

\begin{abstract}
Polyvinyl Alcohol (PVA) based biocomposite film with cellulose was successfully fabricated by the solution casting method. The cellulose fibers were obtained by extraction of durian peel using alkalization and bleaching treatments. These treated cellulose fibers were used for the fabrication of PVAbased biocomposites. The durian peel cellulose fibers were varied by $2 \%, 4 \%, 6 \%$, and $8 \%$ in the PVA matrix. Tensile test and moisture resistance of biocomposites were evaluated. The $6 \%$ addition of cellulose fibers in biocomposites increases the tensile strength up to 54\% (37 MPa) than pure PVA film (24 MPa). Conversely, it reduces the elongation at break of the biocomposite film. Meanwhile, the moisture resistance properties of the biocomposites increased with the addition of cellulose fibers. The tensile strength and moisture resistance of biocomposites have been increased due to the homogeneous dispersion of the cellulose fibers and PVA matrix. These biocomposites able to reduce the environmental impacts by utilizing residual lignocellulosic biomass.
\end{abstract}

Keyword. Polyvinyl Alcohol (PVA); Cellulose fiber; Durian peel fiber; Tensile strength; Moisture resistance

\section{INTRODUCTION}

Polyvinyl alcohol (PVA) is a potential material for the manufacturing of bioplastics because of its biodegradability properties and water solubility [1-3]. PVA is a general bio-plastic with good characterization including chemical resistance and has good gelatin formation. In addition, PVA is medical and packaging applications [4-6]. However, PVA has a high moisture absorption because of the large number of $\mathrm{OH}$ groups [7, 8]. An effort to overcome the weakness is by mixing PVA with a hydrophobic filler such as clay particles or natural fibers $[9,10]$. Recent studies have reported that PVA based biocomposites show higher moisture resistance after the addition of filler such as cellulose nanofibers [11] and nanosilica [12]. The good distribution of the filler in the PVA matrix can be produced using an ultrasonic bath to optimize the tensile and physical properties of the biocomposite film. Previous studies reported the use of ultrasonic baths for the preparation of polyvinyl alcohol films blended with nanofiber [13], montmorillonite [14], halloysite nanoclay
[15], and nanocrystalline cellulose [16] to improve the properties of the biocomposite film. This is due to ultrasonic bath treatment to filler leads to the homogeneous dispersion of the filler in the matrix [17, $18]$.

Ultrasonic bath can improve the polymer structure in matrix which causes changes in its characteristic [19, 20]. The effect of this treatment on the properties of the starch-based biocomposite film was reported in a previous study [21]. The results of this study explain that sonicated films have a more compact and homogeneous polymer structure resulting in higher tensile strength and higher moisture resistance compared to non-sonicated films [21, 22].

From the literature studies, it has been identified that very little work has been focused on the various concentration of durian peel fibers in PVA matrix to develop biocomposite film. Also, from the literature it is well known that, use of cellulose fibers as a reinforcement in biocomposites is one way for improving the environmentally friendly products [2332].

Corresponding author: melbi.mahardika@tbs.itera.ac.id 


\section{MATERIALS AND METHODS}

\subsection{Materials}

Polyvinyl alcohol 2488 CAS number 9002-89-5 was purchased from Prima Global Chemical Ltd., Indonesia. PVA before using it and drying it in an oven at $45^{\circ} \mathrm{C}$ for 20 hours. Other chemicals were purchased from UD. Aneka Kimia (Jember). Durian peel fiber (DPF) was obtained from Durian seller in Jember. The cellulose content of durian peel fiber before extraction was 55$58 \%[33]$.

\subsection{Extraction of Durian Peel Fiber}

Initially, durian peel was cleaned with water until it was clean from dirt. Durian peel was dried for about 3 days until the constant weight under the sun. After that, the durian peel was cut into small pieces. The durian peel was blended at $25000 \mathrm{rpm}$ for 20 minutes until it becomes a fiber powder as previous report [34]. The fiber powder was alkalized using $8 \% \mathrm{NaOH}$ for 2 hours at $60^{\circ} \mathrm{C}$. The fiber was neutralized with distilled water until the $\mathrm{pH}$ becomes 7. Then, it was dried under the sun for 3 hours and formed into sheets of paper fibers.

\subsection{Preparation for PVA/Biocomposite Films}

The 10 gr of PVA pellets were dissolved in $100 \mathrm{~mL}$ of distilled water using a hot plate stirrer (Daihan scientific, model MSH-20D) at $70^{\circ} \mathrm{C}$ and $800 \mathrm{rpm}$ for 1.5 hours until to gel form. The PVA gel was treated ultrasonic bath (BAKU BK-2400) for 10 minutes under $50^{\circ} \mathrm{C}$. After that, it was poured into a petri dish (diameter 150 $\mathrm{mm}$ ) and dried in drying oven (Universal Oven KLAZ) at $60^{\circ} \mathrm{C}$ for 24 hours. Each PVA/biocomposite film was labeled with varying concentrations of durian peel fiber namely PVA-0 (0\% fiber), PVA-2DPF (2\% fiber), PVA4DPF (4\% fiber), PVA-6DPF (6\% fiber) and PVA-8DPF ( $8 \%$ fiber). All of biocomposite films were storaged in Tupperware container size $15 \mathrm{~cm} \mathrm{x} 20 \mathrm{~cm}$ with relative humidity $50 \%$ for one day before characterization.

\subsection{Tensile Test}

The tensile test was performed using a Tensile Machine (Wang Ta type SF093A) to measure modulus of elasticity, elongation at break, and tensile strength. All biocomposite films were cut according to ASTM D88212 standards. Prior to the test, the PVA/biocomposite films were conditioned for 2 days under $50 \pm 5 \%$ relative humidity at $28^{\circ} \mathrm{C}$. The tensile test was repeated three times for each sample.

\subsection{Moisture Absorption}

Moisture absorption (MA) was measured by the same method as previous studies [35]. The PVA and biocomposite films were cut into $2 \mathrm{~cm} \times 2.5 \mathrm{~cm}$ rectangular pieces and dried in drying oven (Universal Oven KLAZ) until constant weight. The $75 \%$ relative humidity $(\mathrm{RH})$ in a closed chamber was used saturated $\mathrm{NaCl}$ solution. The dried PVA/biocomposite films were placed in a closed chamber at $28^{\circ} \mathrm{C}$ for 6 hours and weighed using a precision scale of $0.0001 \mathrm{~g}$ (Kenko KKLAB) every 30 minutes. The MA was calculated using the Equation 1:

$$
\operatorname{MA}(\%)=\left[\left(\mathrm{w}_{\mathrm{t}}-\mathrm{w}_{0}\right) / \mathrm{w}_{0}\right] \times 100
$$

where $\mathrm{w}_{\mathrm{t}}$ final weight sample dan $\mathrm{w}_{0}$ initial weight sample.

\subsection{Scanning Electron Microscopy (SEM)}

The fracture surface of PVA and its biocomposite film after tensile test were observed using scanning electron microscopy (SEM) Hitachi TM3030 Plus. The test was carried out at $5 \mathrm{kV}$ conditions and at room temperature. The fracture sample was formed with a size of $5 \mathrm{~mm} \mathrm{x}$ $12 \mathrm{~mm}$ and coated with gold.

\subsection{Statistical Analysis}

The experimental data analysis was performed using IBM SPSS Statistics 25.0 (IBM Corporation, Chicago, USA). Analysis of variance (ANOVA) were performed to determine the effect of addition fiber in PVA matrix on the tensile and moisture absorption properties. The difference in the mean score of each film was based on Duncan multiple range test, 95\% confidence level $(\mathrm{p} \leq 0.05)$.

\section{RESULT AND DISCUSSION}

\subsection{Tensile Strength}

Figure 1 shows the average values of tensile strength, modulus of elasticity, and elongation at break of pure PVA and its biocomposite films. After the addition of $6 \%$ durian peel fibers, the value of tensile strength was $37 \mathrm{MPa}$ compared to pure PVA film (24 MPa), increased by $54 \%$. The increasing in tensile strength for PVA-DPF was due to the addition of durian peel fibers in matrix as shown in Figure 1. Meanwhile, the elongation at break was improved by $79 \%$ after addition of $6 \%$ DPF compared to pure PVA film. From the ANOVA statistical analysis showed a significant increase in tensile strength along with an increase in the volume of fiber fraction. This is due to the enhancement degree of crystal orientation of the durian peel fibers [36]. This result supported by previous studies the biocomposite PVA/cellulose was higher than PVA film due to the high crystalline structure of PVA [37, 38]. The mechanical strength of cellulose composites for bioplastic applications was important to study because these materials are able to withstand high loads. 

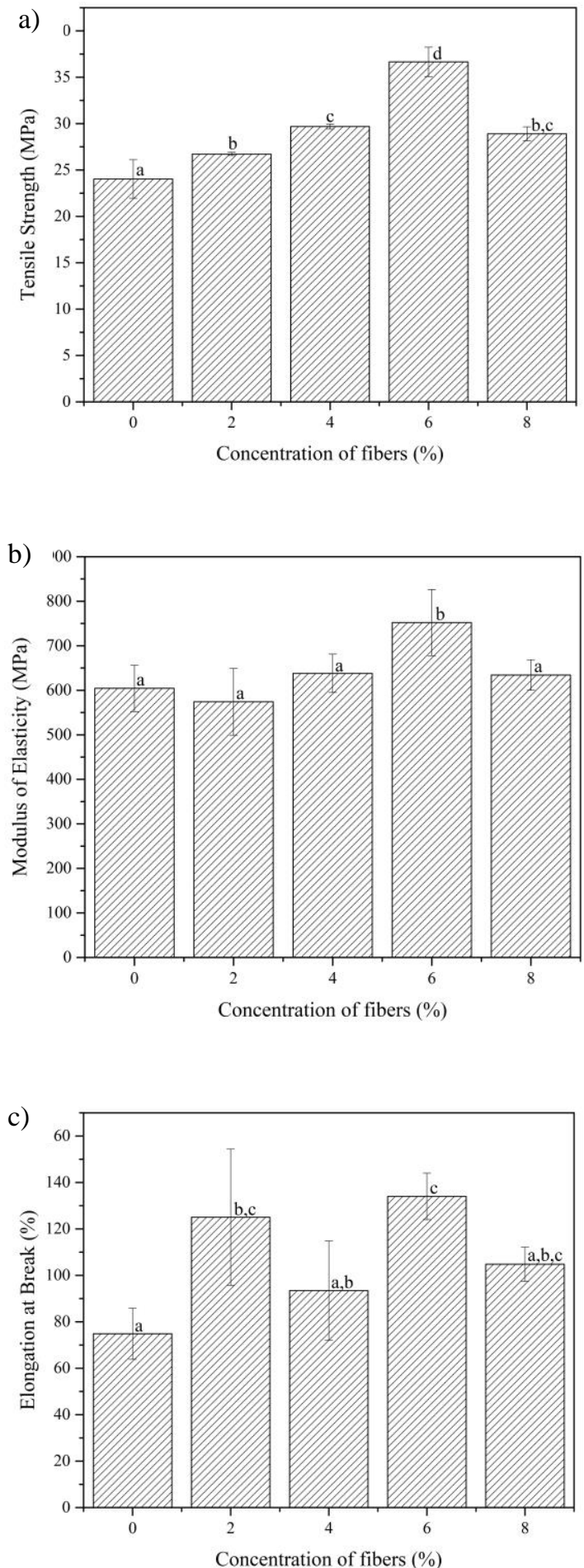

Fig. 1. Tensile Strength (a), Modulus of Elasticity (b), and Elongation at Break (c) for PVA/biocomposite films.

\subsection{Moisture Absorption}

Figure 2 shows the moisture absorption (MA) value of the PVA/biocomposite film. PVA film has the highest MA $(14.2 \%$ after $6 \mathrm{~h})$ due to the much amount of free O$\mathrm{H}$ group [28]. After the addition of the DPF by $2 \%(6 \mathrm{~h})$, the moisture resistance of the film increased. MA for PVA-4DPF (11.3\%) is lower than pure PVA film (14\%) after $6 \mathrm{~h}$. After the fiber fraction increased by $6 \%$, MA decreased again associated with the hydrophilic functional group. For example, after 6 hours in a humid room, the MA for PVA-8DPF was 9.7\%, absorbing $24.8 \%$ less moisture than PVA-2DPF. This is due to the strong intermolecular interactions of the PVA chain via the intermolecular hydrogen bonds. Moisture absorption can diffuse through a hydrophilic film. From the ANOVA statistical analysis data showed the significance of improving moisture resistance along with the increase of the volume fraction DPF. These results are in accordance with previous studies which showed a decrease in moisture absorption in the biocomposite film after the addition of cellulose fibers [8, 11, 38, 39]. Moisture absorption testing was important to ensure that no moisture enters the bioplastic in order to keep the product in good condition.

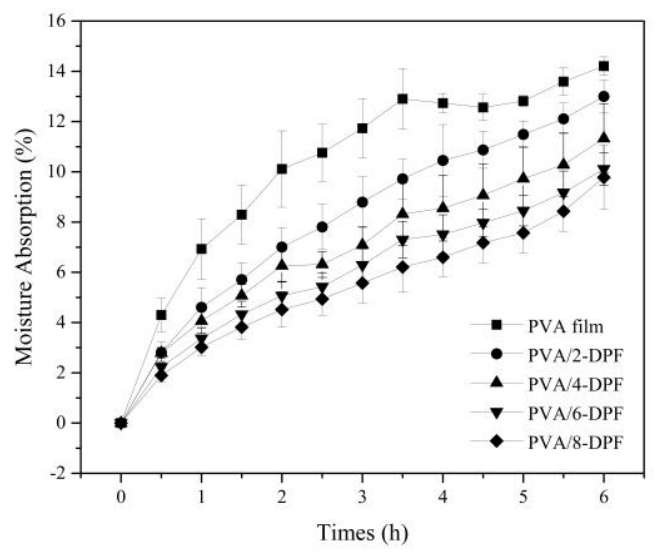

Fig. 2. Moisture Absorption of the PVA/biocomposite films

\subsection{SEM}

Scanning electron microscopy image of fracture surface of the PVA/biocomposite films are shown in Figure 3. Figure 3a showing the smooth surface fracture of pure PVA film. After the addition of $4 \%$ durian peel fiber, the surface of the film becomes rough and wavy like waves. This is due to the contribution of the durian peel fibers that bind to the PVA matrix which makes the polymer chain structure compact as shown in Figure $3 \mathrm{~b}$ (indicated with yellow arrow). Figure $3 \mathrm{c}$ depicts the surface of the PVA/biocomposite films with the addition of $8 \%$ durian skin fibers. In this figure, it can be seen that the surface is getting rougher compared to Figure $3 b$ (indicated with yellow arrow) due to the contribution of the increasing concentration of durian skin fibers in the PVA matrix. These results are supported by previous studies which show the same results $[8,12]$.

\section{CONCLUSION}

This study showed that the addition of DPF significantly increaased the tensile strength and moisture resistance of the PVA/biocomposite film. The results showed that the addition of DPF increased the compatibility of the polymer chain structure as evidenced by the fracture 
surface morphology of SEM. This phenomenon leads to higher tensile strength, and improve moisture resistance properties than pure PVA film. Also shows that the durian peel fibers contribute to improve some of the properties required for food packaging materials. This research needs to be continued further, especially in the characterization of biodegradation and its thermal stability.

a)

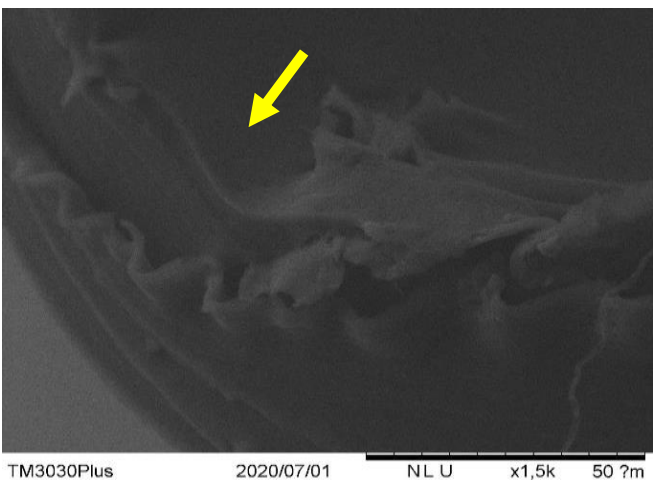

b)

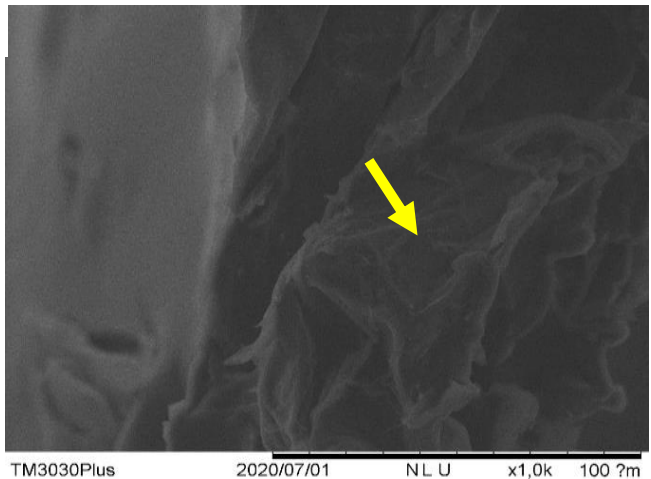

c)

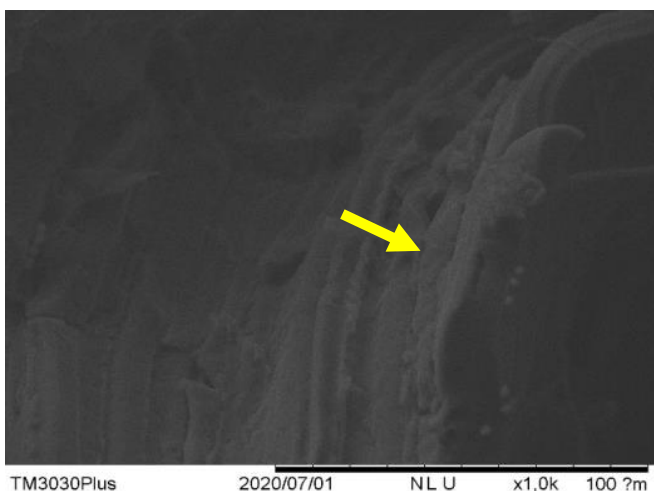

Fig. 3. SEM images of a fracture surface of PVA (a), PVA/biocomposites reinforced with Durian peel fiber (6\%) (b), PVA/biocomposites reinforced with Durian peel fiber (8\%) (c).

\section{Acknowledgements}

This research was supported by Institut Teknologi Sumatera. In addition, researchers are also grateful to the laboratory of material testing, Faculty of Engineering, University of Jember for facilitating research, especially in the manufacture of PVA biocomposite and durian peel fibers.

\section{References}

1. A.I. Cano, M. Cháfer, A. Chiralt, C. GonzálezMartínez, Physical and microstructural properties of biodegradable films based on pea starch and PVA, Journal of Food Engineering, 167, (2015): 59-64

2. D. Domene-López, M.M. Guillén, I. Martin-Gullon, J.C. García-Quesada, M.G. Montalbán, Study of the behavior of biodegradable starch/polyvinyl alcohol/rosin blends, Carbohydrate Polymers, 202, (2018): 299-305

3. Z.W. Abdullah, Y. Dong, Biodegradable and water resistant poly (vinyl) alcohol (PVA)/starch (ST)/glycerol (GL)/halloysite nanotube (HNT) nanocomposite films for sustainable food packaging, Frontiers in Materials, 6, 2019: 58

4. Y. Dou, B. Zhang, M. He, G. Yin, Y. Cui, I. N. Savina, Keratin/polyvinyl alcohol blend films crosslinked by dialdehyde starch and their potential application for drug release, Polymers (Basel), 7, (2015): 580-591

5. J. Zhang, W.R. Xu, Y.C. Zhang, X.D. Han, C. Chen, A. Chen, In situ generated silica reinforced polyvinyl alcohol/liquefied chitin biodegradable films for food packaging, Carbohydr. Polymer, 238, (2020): 116182

6. S. Mathew, A. Jayakumar, V.P. Kumar, J. Mathew, E.K. Radhakrishnan, One-step synthesis of ecofriendly boiled rice starch blended polyvinyl alcohol bionanocomposite films decorated with in situ generated silver nanoparticles for food packaging purpose, International Journal of Biological Macromolecules, 139, (2019): 475-485

7. H. Abral, A. Atmajaya, M. Mahardika, Fadli Hafizulhaq, Kadriadi, D. Handayani, S. M. Sapuan, R. A. Ilyas, Effect of ultrasonication duration of polyvinyl alcohol (PVA) gel on characterizations of PVA film, Journal of Materials Research and Technology, 9, (2020): 2477-2486

8. T. Song, S. Tanpichai, K. Oksman, Cross-linked polyvinyl alcohol (PVA) foams reinforced with cellulose nanocrystals (CNCs), Cellulose, 23, (2016): 1925-1938

9. Z.W. Abdullah, Y. Dong, I.J. Davies, S. Barbhuiya, PVA, PVA blends, and their nanocomposites for biodegradable packaging application, PolymerPlastics Technology and Engineering, 56, (2017): 1307-1344

10. K.E. Bourakadi, N. Merghoub, M. Fardioui, M.E. M. Mekhzoum, I.M. Kadmiri, E.M. Essassi, A.E. K. Qaiss, R. Bouhfid, Chitosan/polyvinyl alcohol/thiabendazoluim-montmorillonite bionanocomposite films: Mechanical, morphological and antimicrobial properties, Composites Part B: Engineering, 172, (2019): 103-110

11. A.N. Frone, C.A. Nicolae, R.A. Gabor, D.M. Panaitescu, Thermal properties of water-resistant starch-polyvinyl alcohol films modified with 
cellulose nanofibers, Polymer Degradation and Stability, 121, (2015): 385-397

12. Y.C. Ching, A. Rahman, K.Y. Ching, N.L. Sukiman, H.C. Cheng, Preparation and characterization of polyvinyl alcohol-based composite reinforced with nanocellulose and nanosilica. BioResources, 10, (2015): 3364-3377

13. Y. Huang, T. Zhou, S. He, H. Xiao, H. Dai, B. Yuan, X. Chen, X. Yang, Flame-retardant polyvinyl alcohol/cellulose nanofibers hybrid carbon aerogel by freeze drying with ultra-low phosphorus, Applied Surface Science, 497, (2019): 143775

14. J. Li, M. Zhou, G. Cheng, F. Cheng, Y. Lin, P.X. Zhu, Fabrication and characterization of starchbased nanocomposites reinforced with montmorillonite and cellulose nanofibers, Carbohydr. Polymer, 210, (2019): 429-436

15. S. Radoor, J. Karayil, J. Parameswaranpillai, S. Siengchin, Adsorption of methylene blue dye from aqueous solution by a novel PVA/CMC/halloysite nanoclay bio composite: Characterization, kinetics, isotherm and antibacterial properties, Journal of Environmental Health Science and Engineering, 18, (2020): 1311-1327

16. N. Noshirvani, W. Hong, B. Ghanbarzadeh, H. Fasihi, R. Montazami, Study of cellulose nanocrystal doped starch-polyvinyl alcohol bionanocomposite films, International Journal of Biological Macromolecules, 107, (2018): 20652074

17. M.J. Dunlop, B. Acharya, and R. Bissessur, Study of plant and tunicate based nanocrystalline cellulose in hybrid polymeric nanocomposites, Cellulose, 27, (2020): 249-261

18. K. Vaezi, G. Asadpour, S.H. Sharifi, Bio nanocomposites based on cationic starch reinforced with montmorillonite and cellulose nanocrystals: Fundamental properties and biodegradability study, International Journal of Biological Macromolecules, 146, (2020): 374-386

19. N.E. Kochkina, O.A. Butikova, Effect of fibrous $\mathrm{TiO} 2$ filler on the structural, mechanical, barrier and optical characteristics of biodegradable maize starch/PVA composite films, International Journal of Biological Macromolecules, 139, (2019): 431439

20. Z. Wu, Y. Huang, L. Xiao, D. Lin, Y. Yang, H, Wang, Y, Yang, D. Wu, H. Chen, Q, Zhang, W. Qin, S. Pu, Physical properties and structural characterization of starch/polyvinyl alcohol/graphene oxide composite films, International Journal of Biological Macromolecules, 123, (2019): 569-575

21. M. Asrofi, H. Abral, Y.K. Putra, S.M. Sapuan, H.J. Kim, Effect of duration of sonication during gelatinization on properties of tapioca starch water hyacinth fiber biocomposite, International Journal of Biological Macromolecules, 108, (2018): 167-176
22. A. Jokar, M.H. Azizi, Z. Hamidi Esfehani, Effects of ultrasound time on the properties of polyvinyl alcohol-based nanocomposite films, Nutrition and Food Sciences Research, 2, (2015): 29-38

23. S.M. Rangappa, S. Siengchin, H.N. Dhakal., Greencomposites: Ecofriendly and sustainability. Applied Science and Engineering Progress, 13, (2020) 183184

24. M.R. Sanjay, S. Siengchin, J. Parameswaranpillai, M. Jawaid, C. I. Pruncu, A. Khan. A comprehensive review of techniques for natural fibers as reinforcement in composites: Preparation, processing and characterization, Carbohydrate Polymers, 207, (2019): 108-121

25. G. Rajeshkumar, G.L. Devnani, J. Prakash Maran, M.R. Sanjay, Suchart Siengchin, Naif Abdullah AlDhabi, K. Ponmurugan. Characterization of novel natural cellulosic fibers from purple bauhinia for potential reinforcement in polymer composites, Cellulose, 28, (2021): 5373-5385

26. M.R. Sanjay, P. Madhu, Mohammad Jawaid, P. Senthamaraikannan, S. Senthil, S. Pradeep. Characterization and properties of natural fiber polymer composites: A comprehensive review. Journal of Cleaner Production, 172, (2018): 566-581

27. A. Vinod, M.R. Sanjay, S. Suchart, P. Jyotishkumar. Renewable and sustainable biobased materials: An assessment on biofibers, biofilms, biopolymers and biocomposites, Journal of Cleaner Production Journal, 258, (2020): 120978

28. M. Ramesh, C. Deepa, L. Rajesh Kumar, M.R. Sanjay, S. Siengchin. Life-cycle and environmental impact assessments on processing of plant fibres and its bio-composites: A critical review, Journal of Industrial Textiles, (2020): 1528083720924730

29. P. Madhu, P.M.R. Sanjay, P. Senthamaraikannan, S. Pradeep, S.S. Saravanakumar, B. Yogesha. A review on synthesis and characterization of commercially available natural fibers: Part II. Journal of Natural Fibers, 16, (2019): 25-36

30. G. Rajeshkumar, S. Arvindh Seshadri, G.L. Devnani, M.R. Sanjay, S. Siengchin, J.P. Maran, N.A. Al-Dhabi, P. Karuppiah, V.A. Mariadhas, N. Sivarajasekar, A.R. Anuf, Environment friendly, renewable and sustainable poly lactic acid (PLA) based natural fiber reinforced composites-A comprehensive reviewJournal of Cleaner Production, (2021): 127483

31. J. Praveenkumara, P. Madhu, T.G. Yashas Gowda, M. R. Sanjay, S Siengchin, A comprehensive review on the effect of synthetic filler materials on fiberreinforced hybrid polymer composites, The Journal of The Textile Institute, (2021): 1-9

32. M.R. Sanjay, S. Siengchin. Editorial corner-a personal view exploring the applicability of natural fibers for the development of biocomposites, Express Polymer Letters, (2021): 193-193 
33. R. Lubis, S.W. Saragih, B. Wirjosentono, E. Eddyanto, Characterization of durian rinds fiber (Durio zubinthinus, murr) from North Sumatera, In AIP Conference Proceedings, 2049, (2018): 1

34. M. Asrofi, H. Abral, A. Kasim, A. Pratoto, Characterization of the microfibrillated cellulose from water hyacinth pulp after alkali treatment and wet blending, In IOP Conference Series: Materials Science and Engineering, 204, (2017): 1

35. M. Mahardika, H. Abral, A. Kasim, S. Arief, F. Hafizulhaq, M. Asrofi, Properties of cellulose nanofiber/bengkoang starch bionanocomposites: Effect of fiber loading, LWT, 116, (2019): 108554.

36. S. Shrestha, F. Montes, G.T. Schueneman, J. F. Snyder, J. P. Youngblood, Effects of aspect ratio and crystal orientation of cellulose nanocrystals on properties of poly (vinyl alcohol) composite fibers, Compos. Science and Technology, 167, (2018): 482-488
37. M. Asrofi, D. Dwilaksana, H. Abral, R. Fajrul, Tensile, thermal, and moisture absorption properties of polyvinyl alcohol (PVA)/bengkuang (pachyrhizuserosus) starch blend films, Material Science Research India, 16, (2019): 70-75

38. H. Abral, J. Ariksa, M, Mahardika, D. Handayani, I. Aminah, N. Sandrawati, S. M. Sapuan, R. A. Ilyas, Highly transparent and antimicrobial PVA based bionanocomposites reinforced by ginger nanofiber, Polymer Testing, 81, (2020): 106186

39. E. Syafri, Sudirman, Mashadi, E. Yulianti, Deswita, M. Asrofi, H. Abral, S.M. Sapuane, R.A. Ilyas, A. Fudholi, Effect of sonication time on the thermal stability, moisture absorption, and biodegradation of water hyacinth (Eichhornia crassipes) nanocellulosefilled bengkuang (Pachyrhizus erosus) starch biocomposites, Journal of Materials Research and Technology, 8, (2019): 6223-6231 